\title{
Results of laparoscopic liver resection: retrospective study of 68 patients
}

\author{
Hitoshi Inagaki · Tsuyoshi Kurokawa · \\ Tadashi Yokoyama · Nobuhiro Ito · \\ Yasuhisa Yokoyama · Toshiaki Nonami
}

Received: 28 November 2007 / Accepted: 25 January 2008/Published online: 20 December 2008

(C) Springer 2008

\begin{abstract}
Background Although an increasing number of reports and publications have dealt with the laparoscopic approach to liver resection, this procedure remains uncommon, and its feasibility, safety and effectiveness are still not established. There are few reports of the advantages of this approach on postoperative recovery.

Methods From December 1997 to March 2007, laparoscopic hepatic resection were performed in 68 patients.

Results There were 52 malignant tumors (36 hepatocellular carcinomas, three intrahepatic cholangiocarcinomas, one cystadenocarcinoma, liver metastases from ten colorectal carcinomas and two other organs) and 16 benign lesions among our 68 patients. Fifteen patients with hepatocellular carcinoma had cirrhosis. The mean tumor size was $3.1 \pm 1.8 \mathrm{~cm}$ (range $1.0-14.0 \mathrm{~cm}$ ), and the tumors were located in every liver segment except segment I. Liver resection was anatomical in 17 patients and consisted of a lobectomy in four patients and a lateral segmentectomy in 13 patients. Non-anatomical resections were performed in 51 patients. The operative time was $214 \pm 93$ min. Mean blood loss was $393 \pm 564$ g. A hand-assisted laparoscopic method or mini-laparotomy method was required in 35 patients $(51.4 \%)$. Operative complications occurred mainly in our early cases and
\end{abstract}

H. Inagaki ( $₫) \cdot$ T. Yokoyama · Y. Yokoyama

Department of Surgery,

Yokoyama Hospital for Gastroenterological Diseases,

3-11-20 Chiyoda, Naka-ku, Nagoya, Aichi 460-0012, Japan

e-mail: h.inagaki@yokoyama-hospital.or.jp

T. Kurokawa $\cdot$ N. Ito $\cdot$ T. Nonami

Department of Surgery, Aichi Medical University,

Yazako Karimata 21, Nagakute-cho, Aichi-gun, Aichi, Japan included three patients (4.4\%) with operative bleeding, 2 of whom (2.9\%) requiring a conversion to open surgery. Postoperative complications occurred in seven patients $(10.0 \%)$, and two of then eventually required a re-operation. The mean hospital stay was 17 days. There were no complications in the more recent cases.

Conclusions The laparoscopic approach for liver tumors is feasible, if the indication is carefully selected. The safety of this procedure depends on the surgical experience of the surgeon and team and the availability of the necessary technology.

Keywords Laparoscopy - Liver resection

\section{Introduction}

Laparoscopic surgery is widely performed for various intraabdominal diseases. In liver surgery, technical progress and improved surgical instruments has enabled the scope for laparoscopic liver resection (LLR) to gradually be broadened. However, this indication is still limited, mainly due to its technical difficulties and the risk of injuring major adjacent vessels on dissection of the hepatic parenchyma. For the successful application of this approach, most experienced liver surgeons must be acquainted with laparoscopic surgery to obtain better exposure and mobilization of the liver. Hence, this procedure is still limited to institutions with surgeons experienced in both hepatic and laparoscopic surgery.

A number of authors have recently been reported the results of their cumulative experience using laparoscopic liver resection [1-8]. In this paper, we report our experience with this technique from the point of view of safety and effectiveness. 


\section{Patients and methods}

From December 1997 to March 2007, our surgical team carried out laparoscopic hepatic resection on 68 patients. The indications for LLR were tumors $<5 \mathrm{~cm}$ located (1) in the left lateral segment (Couinauds segment II and III) or (2) on or near the surface of the liver in segments IV, V, VI and VIII without invasion or adjacent to large vessels, such as the portal pedicle or hepatic veins. We performed LLR on three patients with the tumor located in the posterior segment (segment VII). The indications for major hepatectomy, such as right or left lobectomy, were larger tumors, localized metastatic tumors or benign tumors. The procedure, which had received the approval of the ethical committee in the hospital, was carefully explained to patients, and their informed consent was obtained preoperatively.

\section{Surgical procedure}

Pneumoperitoneum was established using the open method or bladeless trocar (ENDOPATH Xcel; Ethicon Endo-Surgery, Cincinnati, $\mathrm{OH})$. The abdominal pressure was set at $8 \mathrm{mmHg}$. The patient's position and trocar placement were based on the patient's morphology and the type of resection. Three to five trocars (size $12 \mathrm{~mm}$ ) were generally used, and the patient was usually in the supine position. A flexibletype laparoscope (LFT Type V; Olympus, Tokyo Japan) was used in all cases. A mini-laparotomy was performed on one patient using the hand-assisted method and insertion of a Hand Port System (Smith \& Nephew, London, UK) or Gel Port (Applied Medical, Irvine, CA). In the earlier procedures, to avoid gas embolism through the hepatic venous branches, we performed subsequent procedures by the abdominal lifting method, using a Laparolift System (Origin Medsystems, Menlo Park, CA) inserted through the port beneath the umbilicus.

For anatomical resections (right lobectomy, left lobectomy and left lateral segmentectomy), the left or right lobe was first completely mobilized, and then the liver was thoroughly observed by laparoscopic ultrasonography. For right or left lobectomy, to control hemihepatic inflow, we used the method of en masse occlusion of Glisson's sheath of the hilus with a long tape passed through the bifurcation. For left lateral segmentectomy, the portal branch, arterial branch and biliary canal were dissected and then secured with clips or a linear vascular stapler. Instrument fracture of the liver parenchyma was performed using the laparoscopic ultrasonic surgical system (USU; Olympus Optical, Tokyo, Japan) and Harmonic scalpel (Ethicon Endo-Surgery), applying the liver hanging maneuver. Finally, the hepatic vein was sectioned using a linear vascular stapler.
For non-anatomical resections, after observation of the liver by laparoscopic ultrasonography to determine the resection area, we cauterized the transection lines of the liver surfaces with a microwave coagulator (Microtaze; Azwell, Osaka, Japan). The parenchymal transaction was performed using the USU and Harmonic scalpel. The Pringle maneuver was performed in the earlier procedures, but this maneuver has recently become unnecessary.

The resected liver was removed in a plastic bag through a small incision. After specimen removal, the resection surface was inspected, then a single abdominal drain was placed close to the resection surface.

We report here our study of the intra- and postoperative complications and an evaluation of patient follow-up. The data collected include operation time, blood loss, rate of conversion to laparotomy, operative complications and hospital stay. We commenced using the laparoscopic liver resection approach in December 1997, and the principal author has worked at three different hospitals during the 10 -year study period. We therefore compared data for these three periods: A, from December 1997 to December 2002; B, from January 2003 to December 2004; C, from January 2005 to March 2007. Statistical analysis was performed with StatView 5.0 software (SAS, Cary, N.C.) using Student's $t$ test, an analysis of variance (ANOVA) and a logrank test. All $P$ values $<0.05$ were considered to be statistically significant.

\section{Results}

From December 1997 to March 2007, 68 laparoscopic liver resections were performed: period A, 44 patients; period B, 11 patients; period $C, 13$ patients. The 68 patients included 32 females and 36 males, with a mean age of $63.6 \pm 10.9$ years (range 19-81 years). Seven patients (10.3\%) graded Child-Pugh classification B; other patients were classified as A. Of the 68 patients, 52 had malignant tumors and 16 had benign lesions (Table 1). Among those patients with malignant tumors, 36 had hepatocellular carcinoma (HCC) (69.2\%), including 15 patients with liver cirrhosis. The mean size of the resected tumor was $3.1 \pm 1.8 \mathrm{~cm}$ (range $1.0-14.0 \mathrm{~cm}$ ).

The liver resection types are summarized in Table 2, and the resection type was mainly non-anatomical for 51 patients (75\%), including eight atypical segmentectomy and 43 partial liver resections. Nine of 51 patients needed the Pringle maneuver to control bleeding, but this maneuver has not been necessary in more recent procedures. In anatomical resection, we introduced handassisted surgery or dissection of the liver parenchyma through mini-laparotomy in 14 patients. Two right lobectomies were performed for patients with colorectal 
metastasis and two left lobectomies for those with benign tumors.

The mean operative time was $214 \pm 93$ min (range 61$375 \mathrm{~min}$ ). The mean blood loss was $393 \pm 564 \mathrm{ml}$ (range 5-3,500 ml). Bleeding occurred in the transaction of liver parenchyma, and it was difficult to control bleeding from the branch of the hepatic vein. In our early procedures, major blood loss occurred in three patients, and for two of these $(2.9 \%)$, conversion to laparotomy was required due to the difficulty in controlling intraoperative hemorrhage.

Postoperative complications were experienced by 18 patients (Table 3). There was no mortality. Bile leakage of the liver stump of one patient who had undergone an atypical segmentectomy IV and hemorrhage from the liver stump of another patient who had undergone a partial resection required re-operation.

Table 1 Patient background

\begin{tabular}{|c|c|c|c|c|}
\hline $\begin{array}{l}\text { Demographic-clinical } \\
\text { parameters }^{\mathrm{a}}\end{array}$ & $\begin{array}{l}\text { A } \\
(n=44)\end{array}$ & $\begin{array}{l}\mathrm{B} \\
(n=11)\end{array}$ & $\begin{array}{l}\mathrm{C} \\
(n=13)\end{array}$ & $\begin{array}{l}P \\
\text { value }\end{array}$ \\
\hline $\begin{array}{l}\text { Age, years } \\
\quad(\text { mean } \pm \mathrm{SD})\end{array}$ & $62.8 \pm 11.6$ & $62.4 \pm 8.0$ & $67.1 \pm 10.9$ & NS \\
\hline Male:female & $22: 22$ & $5: 6$ & $9: 4$ & NS \\
\hline $\begin{array}{r}\text { Anatomical } \\
\text { resection }\end{array}$ & $9(20 \%)$ & $4(36 \%)$ & $5(38.5 \%)$ & NS \\
\hline $\begin{array}{l}\text { HALS (mini- } \\
\text { laparotomy) }\end{array}$ & $20(3)$ & $8(4)$ & $7(4)$ & NS \\
\hline Liver cirrhosis & 12 & 1 & 2 & NS \\
\hline $\begin{array}{l}\text { Size of tumor, } \mathrm{cm} \\
\quad(\text { mean } \pm \mathrm{SD})\end{array}$ & $3.0 \pm 1.1$ & $3.1 \pm 0.9$ & $2.7 \pm 1.1$ & NS \\
\hline $\mathrm{HCC}$ & $23(52 \%)$ & $7(63.6 \%)$ & $6(46.2 \%)$ & NS \\
\hline Metastatic tumors & $4(9 \%)$ & $3(27.3 \%)$ & $5(38.5 \%)$ & NS \\
\hline $\begin{array}{l}\text { Other malignant } \\
\text { tumors }\end{array}$ & $4(9 \%)$ & 0 & 0 & NS \\
\hline Benign lesions & $9(30 \%)$ & 1 & 2 & NS \\
\hline
\end{tabular}

$\mathrm{A}, \mathrm{B}, \mathrm{C}$ indicate the three time intervals being compared, corresponding the principal author's surgical experience at three different hospitals. A, from December 1997 to December 2002; B, from January 2003 to December 2004; C, from January 2005 to March 2007

${ }^{a} H A L S$ hand-assisted laparoscopic surgery, HCC hepatocellular carcinoma
In terms of the postoperative period, patient characteristics and data in each of the three periods were similar for all factors (Table 4). Although the operative time was similar in all three periods, blood loss tended to decrease in period C. Conversion to the open method occurred in two cases only in the early phase of period A. Seven cases in period A had postoperative complications, with two patients requiring re-operation.

Figure 1 shows the Kaplan-Meier curve of the laparoscopic liver resection for hepatocellular carcinoma. The 5year survival rate $(79.3 \%)$ was similar to the results of open hepatectomy at the three hospitals. From December 1997 to June 2005, we compared laparoscopic hepatectomy and open method hepatectomy for metastatic liver tumors from colorectal cancer. Although there were no differences in postoperative survival, the patient number was small (Fig. 2).

\section{Discussion}

Although the laparoscopic approach is increasingly being used in general surgery, the indication for LLR is still

Table 3 Postoperative complications

\begin{tabular}{lllll}
\hline Postoperative complications & A & B & C & Total \\
\hline Specific morbidity & 9 & 0 & 0 & $9(13.2 \%)$ \\
Re-operation & 2 & 0 & 0 & 2 \\
Blood collection & $1^{\mathrm{a}}$ & 0 & 0 & 2 \\
Biliary collection & 3 & 0 & 0 & 3 \\
Stenosis of hepatic duct & $1^{\mathrm{a}}$ & 0 & 0 & 1 \\
Perforation of the duodenum & 1 & 0 & 0 & 1 \\
Lymphorrhea & 1 & 0 & 0 & 1 \\
Portsite recurrence & 0 & 0 & 0 & 0 \\
General morbidity & 6 & 2 & 1 & $9(13.2 \%)$ \\
Liver function disorder & 2 & 1 & 1 & 4 \\
Cardiac failure & 2 & 0 & 0 & 2 \\
Trocar-site bleeding & 1 & 0 & 0 & 1 \\
Wound infection & 1 & 1 & 0 & 2 \\
\hline
\end{tabular}

\footnotetext{
${ }^{\text {a }}$ Re-operation
}

Table 2 Liver resection types

\begin{tabular}{lllll}
\hline Surgical approach & A $(n=44)$ & B $(n=11)$ & C $(n=13)$ & Total \\
\hline Anatomical resection & $8(18 \%)$ & $4(36.4 \%)$ & $5(38.5 \%)$ & $2(15.4 \%)$ \\
Right hepatectomy (Seg. V, VI, VII, VIII) & 0 & 0 & 0 & $2(2.9 \%)$ \\
Left hepatectomy (Seg. II, III, IV) & $2(4.5 \%)$ & 0 & $3(23.1 \%)$ & $2(2.9 \%)$ \\
Left lateral segmentectomy (Seg. II, III) & $6(13.6 \%)$ & $4(36.4 \%)$ & $7(61.5 \%)$ & $13(19.2 \%)$ \\
Non-anatomical resection & $36(82 \%)$ & $1(7.7 \%)$ & $81(75 \%)$ \\
Segmentectomy & $7(16 \%)$ & $6(54.5 \%)$ & $7(53.8 \%)$ & $43(63.2 \%)$ \\
Partial resection & $29(66 \%)$ & & \\
\hline
\end{tabular}


Table 4 Comparison of postoperative results

\begin{tabular}{|c|c|c|c|c|}
\hline $\begin{array}{l}\text { Postoperative } \\
\text { variables }\end{array}$ & A $(n=44)$ & $\mathrm{B}(n=11)$ & $\mathrm{C}(n=9)$ & $\begin{array}{l}P \\
\text { value }\end{array}$ \\
\hline Operative time (min) & $217 \pm 105$ & $187 \pm 50$ & $227 \pm 80$ & NS \\
\hline Blood loss (ml) & $450 \pm 679$ & $300 \pm 232$ & $262 \pm 233$ & NS \\
\hline Hospital stay (days) & $16.6 \pm 13.0$ & $15.0 \pm 6.7$ & $14.8 \pm 7.1$ & NS \\
\hline Conversion & 2 & 0 & 0 & NS \\
\hline $\begin{array}{l}\text { Postoperative specific } \\
\text { morbidity }\end{array}$ & 9 & 0 & 0 & NS \\
\hline $\begin{array}{l}\text { Postoperative general } \\
\text { morbidity }\end{array}$ & 6 & 2 & 1 & NS \\
\hline
\end{tabular}

Values are given as the mean \pm standard deviation

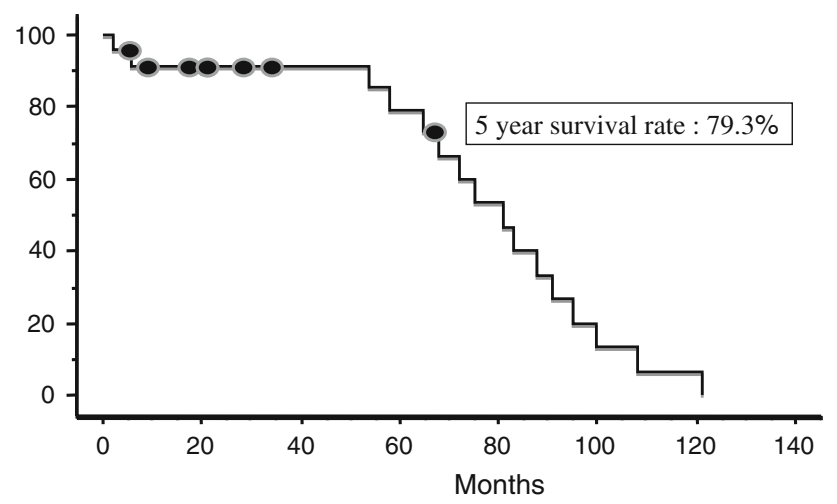

Fig. 1 Postoperative survival of hepatocellularcarcinoma following laparoscopic liver resection (LLR) (Kaplan-Meier)

limited $[2,6]$, primarily due to the difficulty involved in mobilizing the liver and the risk of injury to major branches of the hepatic vein during dissection of the hepatic parenchyma. We commenced using the laparoscopic approach in 1997 and have gradually increased our expertise over the past decade. In deciding for the LLR approach, especially for an atypical partial resection, we consider the size and site of lesions in relation to major vessels. As our learning curve has advanced, the rate of LLR being used in liver resections has been increasing.

In previous studies, the rate of benign lesions for LLR was high $[1,2]$ because the lesions were in the normal liver, not in chronic damaged liver [4]. Based on our cases, the resection rate of malignant lesions was $76.5 \%$, including 15 cases of HCC with liver cirrhosis. In other studies, LLR for liver cirrhosis patients with poor hepatic function was performed with good results $[2,9,10]$.

We have experienced only nine cases $(13.2 \%)$ of specific complications, including two patients requiring reoperation in the early phase (one for hemorrhage and another for stenosis of the intra-hepatic bile duct), and three cases of biliary collection and perforation of the duodenum (due to the microwave coagulator in the initial case). No specific complications have been recognized in

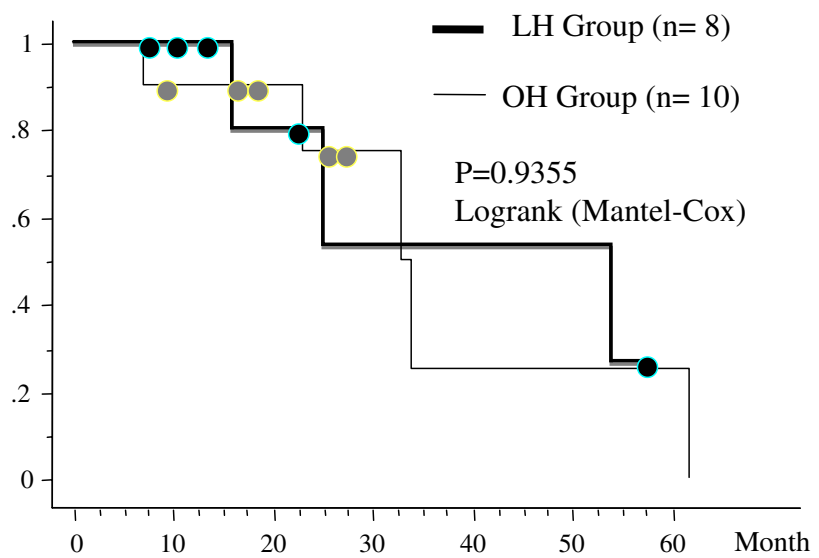

Fig. 2 Postoperative survival of metastasis (Kaplan-Meier) in the laparoscopic hepatectomy $(L H)$ group versus that in the open method hepatectomy $(\mathrm{OH})$ group from December 1997 to June 2005

the more recent cases. The rate of general complications was $13.2 \%$, and there were no uncontrollable ascites, even patients with cirrhosis.

The conversion rate to the open method was relatively low [2, 6, 8, 9], and as our learning curve advanced, it became very low [3]. Only during our early cases were there two cases of conversion because of hemorrhage from the stump of the liver. Failure to control bleeding is one of the most important reasons for conversion to the open method $[2,4,6]$. This problem has not been completely solved technically, but the LLR technique and equipment for laparoscopic surgery continue to improve.

The Pringle maneuver was useful to control hemorrhage [11], which involves clamping the hepatoduodenal ligament in partial resection and anatomical resection [12] in patients with liver cirrhosis. However, the need for this maneuver has decreased with our learning curve.

The Harmonic scapel is a very useful surgical tool for reducing blood loss, and we used a microwave coagulator on the liver surface cutting line before dissection of the parenchyma [13]. Argon beam coagulation is also useful, but care should be taken not to increase intra-abdominal pressure [14]. The appropriate use of endo-linear staplers in anatomical resection reduces specific complications and operation time $[15,16]$.

We modified the completely laparoscopic operations into the hand-assisted technique by slightly extending the incision for the removal of the liver from the beginning in those cases where the tumors were located in the posterior segment and/or segment 8 , with the tumor $>3 \mathrm{~cm}$. Our opinion is that this technique may be safely and effectively applied in LLR [12, 17-20] due to its technical advantages. First, direct manipulation by the surgeon's hand enables visualization of the surgical field, which is rather similar to open surgery. Second, immediate hemostasis can be brought about by depressing the bleeding point, especially in cases of bleeding 
from hepatic venous branches $[10,12,20]$. Third, guidance by the surgeon's hand has proven to be useful in radiofrequency ablation therapy for other small lesions, if necessary.

In some reports, the operative time required for the LLR was significantly longer than that for open surgery [21, 22]. Comparative studies have shown that mortality and morbidity were not increased by LLR, that the operative time was similar or slightly longer, that blood loss was similar or lower and that the mean hospital stay was shorter patients undergoing $\operatorname{LLR}[5,7,22,23]$.

The efficacy of LLR for malignant lesions is attested to by good overall survival rates. The results of our study show the same results in patients with HCC and in those with metastasis from colorectal cancer (MCR). The 5-year overall survival rate after LLR for HCC was 79.3\%, which compares favorably with previous reports of that with the open method [9, 21, 24-26]. Based on the cases included in the study reported here, we found no differences between the laparoscopic approach and open method $[6,7,27]$ in terms of overall survival rate after LLR for MCR and those reported in a previous study, For MCR, the laparoscopic technique also has the advantage of minimal scarring and fewer adhesions, thereby increasing the feasibility of repeat liver resection.

In conclusion, although operative safety depends on the extent of surgical experience and technological availability, the laparoscopic approach for liver tumors is quite feasible, including that for major hepatectomy for malignancy. Future studies with large numbers of patients and long-term follow-up are warranted in order to draw more precise conclusions on the role of the laparoscopic approach in liver surgery.

\section{References}

1. Borzellino G, Ruzzenente A, Minicozzi AM, Giovinazzo F, Pedrazzani C, Guglielmi A. Laparoscopic hepatic resection. Surg Endosc. 2006;20:787-90.

2. Cherqui D, Husson E, Hammoud R, Malassagne B, Stephan F, Bensaid S, et al. Laparoscopic liver resections: a feasibility study in 30 patients. Ann Surg. 2000;232:753-62.

3. Dagher I, Proske JM, Carloni A, Richa H, Tranchart H, Franco D. Laparoscopic liver resection: results for 70 patients. Surg Endosc. 2007;21:619-24.

4. Descottes B, Glineur D, Lachachi F, Valleix D, Paineau J, Hamy A, et al. Laparoscopic liver resection of benign liver tumors. Surg Endosc. 2003;17:23-30.

5. Farges O, Jagot P, Kirstetter P, Marty J, Belghiti J. Prospective assessment of the safety and benefit of laparoscopic liver resections. J Hepatobiliary Pancreat Surg. 2002;9:242-8.

6. Gigot JF, Glineur D, Santiago Azagra J, Goergen M, Ceuterick M, Morino M, et al. Laparoscopic liver resection for malignant liver tumors: preliminary results of a multicenter European study. Ann Surg. 2002;236:90-7.

7. Mala T, Edwin B, Rosseland AR, Gladhaug I, Fosse E, Mathisen O. Laparoscopic liver resection: experience of 53 procedures at a single center. J Hepatobiliary Pancreat Surg. 2005;12:298-303.
8. Vibert E, Perniceni T, Levard H, Denet C, Shahri NK, Gayet B. Laparoscopic liver resection. Br J Surg. 2006;93:67-72.

9. Cherqui D, Laurent A, Tayar C, Chang S, Van Nhieu JT, Loriau $\mathrm{J}$, et al. Laparoscopic liver resection for peripheral hepatocellular carcinoma in patients with chronic liver disease: midterm results and perspectives. Ann Surg. 2006;243:499-506.

10. Inagaki H, Kurokawa T, Nonami T, Sakamoto J. Hand-assisted laparoscopic left lateral segmentectomy of the liver for hepatocellular carcinoma with cirrhosis. J Hepatobiliary Pancreat Surg.. 2003;10:295-8.

11. Haberstroh J, Ahrens M, Munzar T, Waninger J, Salm R, Matern $\mathrm{U}$, et al. Effects of the Pringle maneuver on hemodynamics during laparoscopic liver resection in the pig. Eur Surg Res. 1996;28:8-13.

12. Inagaki H, Kurokawa T, Sakamoto J, Nonami T. Laparoscopic left hemihepatectomy combined with right hemicolectomy for liver tumor and hemorrhagic diverticulosis. Surg Endosc. 2003;17:158-9.

13. Tabuse K. Basic knowledge of a microwave tissue coagulator and its clinical applications. J Hepatobiliary Pancreat Surg. 1998; 5:165-72.

14. Hashizume M, Takenaka K, Yanaga K, Ohta M, Kajiyama K, Shirabe K, et al. Laparoscopic hepatic resection for hepatocellular carcinoma. Surg Endosc. 1995;9:1289-91.

15. Azagra JS, Goergen M, Gilbart E, Jacobs D. Laparoscopic anatomical (hepatic) left lateral segmentectomy-technical aspects. Surg Endosc. 1996;10:758-61.

16. Belli G, Fantini C, D’Agostino A, Belli A, Cioffi L, Russolillo N. Laparoscopic left lateral hepatic lobectomy: a safer and faster technique. J Hepatobiliary Pancreat Surg. 2006;13:149-54.

17. Antonetti MC, Killelea B, Orlando R 3rd. Hand-assisted laparoscopic liver surgery. Arch Surg. 2002;137:407-12.

18. Fong Y, Jarnagin W, Conlon KC, DeMatteo R, Dougherty E, Blumgart LH. Hand-assisted laparoscopic liver resection: lessons from an initial experience. Arch Surg. 2000;135:854-9.

19. Huang MT, Lee WJ, Wang W, Wei PL, Chen RJ. Handassisted laparoscopic hepatectomy for solid tumor in the posterior portion of the right lobe: initial experience. Ann Surg. 2003; 238:674-9.

20. Kurokawa T, Inagaki H, Sakamoto J, Nonami T. Hand-assisted laparoscopic anatomical left lobectomy using hemihepatic vascular control technique. Surg Endosc. 2002;16:1637-8.

21. Laurent A, Cherqui D, Lesurtel M, Brunetti F, Tayar C, Fagniez PL. Laparoscopic liver resection for subcapsular hepatocellular carcinoma complicating chronic liver disease. Arch Surg. 2003; 138:763-9.

22. Lesurtel M, Cherqui D, Laurent A, Tayar C, Fagniez PL. Laparoscopic versus open left lateral hepatic lobectomy: a casecontrol study. J Am Coll Surg. 2003;196:236-42.

23. Morino M, Morra I, Rosso E, Miglietta C, Garrone C. Laparoscopic vs open hepatic resection: a comparative study. Surg Endosc. 2003;17:1914-8.

24. Belghiti J, Panis Y, Farges O, Benhamou JP, Fekete F. Intrahepatic recurrence after resection of hepatocellular carcinoma complicating cirrhosis. Ann Surg. 1991;214:114-7.

25. Kaneko H, Takagi S, Otsuka Y, Tsuchiya M, Tamura A, Katagiri $\mathrm{T}$, et al. Laparoscopic liver resection of hepatocellular carcinoma. Am J Surg. 2005;189:190-4.

26. Yamamoto J, Okada S, Shimada K, Okusaka T, Yamasaki S, Ueno H, et al. Treatment strategy for small hepatocellular carcinoma: comparison of long-term results after percutaneous ethanol injection therapy and surgical resection. Hepatology. 2001;34:707-3.

27. Reza MM, Blasco JA, Andradas E, Cantero R, Mayol J. Systematic review of laparoscopic versus open surgery for colorectal cancer. Br J Surg. 2006;93:921-8. 